\title{
[rhyme of the ancient urinal]
}

\section{klipschutz}

“Duchamp's pissoir I am, monsieur, no other Too many pigs have watered my cup since But yes, you are a cynic, with good reason Displaced, I lack all power to convince

You find me filthy, common junk my neighbors

(I, who crowds filed past in Sunday hush) Among slit-wristed tubs, old pipe, sad toilets My confidante Lautrec's last whore's last crutch

Death came from high and low and then the vandals Took everything they could not eat or burn They sprayed their poison stream and spat blood juices

Fate moved me wall to wall to here, a chess piece out of turn

You hear me plain yet doubt your very wits

I doubt them too, beware, the spigot drips"

[2087] 